\title{
NOVOS CONTEXTOS, NOVOS PADRÕES: O MERCADO IMOBILIÁRIO E OS REARRANJOS NA MOBILIDADE ESPACIAL DA POPULAÇÃO NA REGIÃO METROPOLITANA DO RIO DE JANEIRO ${ }^{1}$
}

\section{New contexts, new standards: the real estate market and rearrangements in the spacial mobility of the population in the metropolitan area of Rio de Janeiro}

\author{
Faber Paganoto \\ faberpaganoto@gmail.com
}

Artigo recebido em 11/09/2012 e aceito para publicação em 20/09/2012

RESUMO: O espaço geográfico, muito mais do que receptáculo, é reflexo e condição da produção e da reprodução social, este ensaio busca identificar, dimensionar e analisar possíveis mudanças nos padrões de mobilidade espacial da população na Região Metropolitana do Rio Janeiro, como efeito do processo de recuperação econômica de sua periferia ao longo da última década.

Considera-se, aqui, que os novos empreendimentos imobiliários lançados nos municípios da Baixada Fluminense, sobretudo em Nova Iguaçu, Duque de Caxias e São Gonçalo, em função de seu volume e de seu perfil voltado principalmente às populações de classe média, têm papel fundamental no entendimento destes rearranjos da mobilidade, seja sobre a migração ou sobre os deslocamentos intrametropolitanos.

Os investimentos imobiliários, ao mudar o padrão de uso e o valor do solo, deslanchariam um processo de invasão-sucessão, empurrando os mais pobres para municípios menos dinâmicos da própria periferia, não necessariamente rompendo com seus vínculos empregatícios no município de origem. Assim, os deslocamentos pendulares originados na periferia e destinados a outro município na periferia tenderiam a se intensificar. Além disso, a ampliação da oferta de empregos durante as obras (construção civil) e depois das obras (setores de manutenção, limpeza, segurança e serviços domésticos), ratificaria o fortalecimento de novos núcleos de destino para os deslocamentos pendulares na periferia metropolitana.

Palavras-chave: Mobilidade, Pendularidade, Metrópole, Mercado imobiliário

ABSTRACT: The space is the result and the condition of production and reproduction of society, this essay seeks to identify, measure and analyze possible changes in patterns of spatial mobility of population in the metropolitan region of Rio Janeiro, as an effect of economic recovery process of its periphery over the past decade.

It is considered here that the new real estate projects launched in the municipalities of the Baixada Fluminense, particularly in Nova Iguaçu, Duque de Caxias and São Gonçalo, because of their size and because they targeted mainly at middle-class populations, are key in understanding these rearrangements of mobility, either on migration or on the intrametropolitan displacements.

The real estate investments, by changing the pattern of use and value of land, start a process of invasion-succession, pushing the poorest population for the least dynamic municipalities of periphery, not necessarily breaking their employment contracts in the previous municipality. Thus, commuting originated in the periphery and destined for another city also in the periphery tend to intensify. Furthermore, the increase of jobs during and after construction (sectors of maintenance, cleaning, security and housekeeping, for example), ratify the strengthening of new nuclei destination for commuting in the metropolitan periphery.

Key words: Mobility, Commuting, Metropolis, Real state market 


\section{APRESENTAÇÃO}

A cidade é a concretização espacial dos processos sociais e, ao refletir as características da sociedade, está em constante processo de reorganização (Harvey, 1972 e Corrêa, 1996). A metrópole moderna, produto da economia de mercado, é a expressão mais bem acabada da complexa sociedade estratificada contemporânea (Harvey, 1975), cujo tecido urbano é marcado por desigual distribuição de bens e serviços, configurando uma forte diferenciação sócioespacial. Mudam as sociedades, mudam as cidades. Complexificam-se as sociedades, complexificam-se as formas de organização da metrópole. O espaço tem uma dimensão social importantíssima, não sendo mero suporte físico para os processos sociais.

Assim, o objetivo deste estudo é identificar, dimensionar e analisar as mudanças e as tendências da mobilidade espacial da população no contexto da Região Metropolitana do Rio de Janeiro, como implicações do crescimento econômico, das transformações no mundo e no mercado de trabalho, da heterogeneização social e da resignificação de sua periferia. Um agente espacial de fundamental importância nesta análise será o mercado imobiliário, que tem crescido de modo muito significativo nos municípios da Baixada Fluminense, com destaque para o município de Nova Iguaçu.

Estudos recentes (Jardim, 2007; Lago, 2008) sugerem a superação da noção tradicional do conceito de periferia, que segundo Kowarick (1983), qualifica um determinado território na metrópole pelo conjunto de carências ali observadas e não encontrado em outro lugar: carência de serviços públicos básicos, de urbanização das áreas públicas, de titularidade da propriedade e de proximidade do mercado de trabalho, entre outras. Essa superação estaria associada à emergência da periferia metropolitana também como lugar do trabalho.

Os resultados do Censo Demográfico 2000 indicaram uma forte mudança no percentual e no volume de pessoas que não saíam de seu próprio município de residência na periferia metropolitana, diariamente, para trabalhar: 63\% dos ocupados trabalhavam, em 2000, no município em que moravam, o que representava cerca de um milhão de pessoas, enquanto em 1980, esse percentual era de 48\%, equivalendo a cerca de 590 mil pessoas (Lago, 2008). Em síntese, houve uma redução da mobilidade casa-trabalho para os moradores da periferia levando a crer que o mercado de trabalho não só se expandiu nessas áreas, mas absorveu parte da mão de obra local.

Paralelamente, o crescente número de lançamentos imobiliários nos municípios da periferia poderia estar promovendo uma mudança significativa nos padrões de usos do solo, valorizando certos espaços e forçando os mais pobres a mudarem seu local de residência. Além disso, estes empreendimentos ampliam a oferta de emprego para atividades que exigem baixa qualificação e oferecem baixa remuneração, tanto durante as obras, na construção civil, como após as obras, nos serviços de manutenção, vigilância e limpeza dos condomínios e das unidades habitacionais. Deste modo, haveria uma reorganização dos deslocamentos populacionais no contexto da periferia da metrópole.

Os dados e as evidências permitem refletir sobre o surgimento de uma nova pendularidade cujo deslocamento seria mais curto e envolveria a periferia e novos 'núcleos dinâmicos' na própria periferia metropolitana, somando-se a já tradicional mobilidade casatrabalho de mais longa distância entre a periferia e o núcleo metropolitano. E, ainda, seria possível afirmar que a dinamização da economia da periferia esteja atraindo trabalhadores residentes no núcleo da metrópole? Estaríamos diante da ruptura da velha concepção da periferia como região-dormitório? 


\section{REFLEXÕES SOBRE METRÓPOLE E MOBILIDADE ESPACIAL DA POPULAÇÃO}

Segundo Santos (1996), as metrópoles continuarão a crescer, apesar de sua "involução metropolitana", com a coexistência de atividades com diversos níveis de capital, tecnologia, organização e trabalho: por sua própria composição orgânica do capital e do espaço, permitem a convivência dentro do seu espaço de capitais (e trabalhos) os mais diversos. Donde, poderão continuar a receber imigrantes e a acolher populações pobres e despreparadas.

A volta da importância da metrópole é trazida por Davidovich (2004), ao destacar entre as outras formas de concentração urbana no Brasil (aglomerações urbanas não metropolitanas e cidades com mais de 100.000 habitantes) a ocorrência de 26 regiões metropolitanas institucionalizadas, quando não passavam de nove na década de 1970, e ao mensurar o universo metropolitano que em 2000 reunia mais de 64,5 milhões de pessoas, representando $38 \%$ do total da população brasileira.

Convém constatar que a taxa média anual de crescimento populacional das metrópoles, tomadas em conjunto, teria sido de 2,1\% entre 1991 e 2000, superando a do país, estimada no intervalo de $1,6 \%$ a $1,9 \%$, sugerindo uma inversão do que ocorreu no período censitário anterior, quando os valores corresponderam, respectivamente a $1,8 \%$ e $1,9 \%$. O ritmo de crescimento das metrópoles brasileiras apresentou-se, entretanto, diferenciado na última década. No caso do Rio de Janeiro, enquanto a metrópole apresentava baixa taxa de crescimento $(0,74 \%)$, municípios de seu entorno cresciam a taxas bem mais elevadas, conferindo ao conjunto da Região Metropolitana uma taxa média geométrica anual de 1,12\%, refletindo assim a disparidade do crescimento intrametropolitano e um movimento de maior periferização da metrópole.

Paralelo ao crescimento populacional diferenciado das células metropolitanas cabe uma referência às mudanças no perfil funcional da metrópole, em decorrência da realização de investimentos produtivos e em infra-estrutura, capacitando-a como centro de serviços em detrimento das atividades fabris. De acordo com Oliveira (2005) a cidade do Rio de Janeiro tende a se consolidar como um importante centro empresarial de informática, que já reúne importantes empresas de software, "cidade informacional respaldada na expansão de setores da nova economia" (Davidovich,2004:213), além de ter reorganizada a infra-estrutura de turismo. Assim, na medida em que há uma redução do número de empresas industriais, amplia-se também o desemprego e a exclusão social.

Quanto ao mercado de trabalho formal torna-se cada vez mais especializado na metrópole, privilegiando os segmentos de maior renda. De outro lado, a precarização das relações de trabalho e a pressão do mercado imobiliário contribuem para o aumento da mobilidade da população trabalhadora de baixa renda em direção ás áreas mais periféricas do complexo metropolitano, ou para áreas centrais menos privilegiadas em termos de sitio e de serviços de infra-estrutura urbana básica. Neste sentido, a segregação residencial expressa o perfil diferenciado de sua população, isto é, "a separação espacial das diferentes classes fragmentadas" (Corrêa, 1989:66). A desigualdade, presente no processo de crescimento dos complexos metropolitanos ", inevitável e necessária ao capitalismo (Browett,1984; Walker, 1978) pode ser vista também como "diferenciação sócio-espacial. Segundo Corrêa (2006) as diferenças sócio-espaciais constituem simultaneamente reflexo, meio e condição para o funcionamento e reprodução do sistema capitalista.

Entretanto, esse processo deve ser relativizado. Até a década de 1980 a Região Metropolitana do Rio de Janeiro (RMRJ) expressava a clássica oposição centro x periferia ${ }^{2}$. Esta diferenciação se dava tanto no nível econômico, com o núcleo da metrópole ocupando a 
condição de lugar do trabalho pela concentração das atividades industriais, além de comércio e serviços, quanto nos níveis social e político. Grande parte da população residente nos municípios da periferia metropolitana deslocava-se diariamente para trabalhar na cidade do Rio de Janeiro, retornando para casa ao fim do dia. A periferia era, em grande medida, onde se dormia.

A partir dos anos 90 grandes mudanças são observadas no espaço metropolitano. Se por um lado o núcleo metropolitano passa por uma involução, atraindo menos investimentos e menos migrantes, por outro a periferia vivencia uma dinamização econômica decorrente da desconcentração industrial, colocando em xeque o modelo da dualidade centro x periferia pelo menos no que tange à RMRJ.

Como resultado do aquecimento econômico da periferia da RMRJ duas novas configurações sócio-espaciais se delineiam: a periferia começa a ser pensada, também, como lugar do trabalho (Lago, 2008), e observa-se uma heterogeneização percebida através do enobrecimento da periferia (Jardim, 2007).

No período 1980-2000, a elevação significativa do percentual e também do volume de ocupados no município de residência na RMRJ, indicando a redução da mobilidade casatrabalho de longa distância, reitera a concepção da periferia como lugar do trabalho. No mesmo período observou-se também o surgimento de condomínios residenciais exclusivos na Baixada Fluminense, que estariam sendo procurados como alternativa segura e exclusiva de moradia por uma classe média, que segundo Jardim (2007), seria residente na própria periferia.

Desde o final dos anos 1990, grandes intervenções se concretizaram nos espaços periféricos da RMRJ e, mais recentemente, diversos projetos e políticas foram anunciados, o que pode ter aprofundado ou mesmo consolidado as tendências anteriormente apontadas.

Entre as intervenções de grande impacto na economia e, possivelmente, na mobilidade espacial da população, mas cujas consequiências não puderam ser captadas pelo Censo Demográfico 2000, destacam-se a: i) modernização do porto de Itaguaí, iniciada em 1998, ano em que houve a quebra do monopólio estatal na operação de portos públicos; ii) a inauguração da Via Light (RJ-081), também em 1998, cortando os municípios de Nova Iguaçu, Mesquita, Nilópolis e São João de Meriti, e sua integração com a estrada de Madureira, no Rio de Janeiro, aprovada em abril de 2008 (ainda não concluída); iii) a abertura de grandes centros comerciais nos municípios da periferia, como Shopping Grande Rio, em São João de Meriti (inaugurado em 1995 e expandido em 2004, com outra expansão programada para 2010), Nilópolis Square (inaugurado em 2000), em Nilópolis, São Gonçalo Shopping (inaugurado em 2004) e Boulevard Shopping (com inauguração prevista para 2010), ambos em São Gonçalo, Caxias Shopping (inaugurado em 2008), em Duque de Caxias.

Grandes projetos públicos e privados prometem intensificar a geração de empregos, a entrada de capitais e a atração de população para a região, como, por exemplo, a: i) construção do Arco Rodoviário Metropolitano, já iniciada, que terá quase 150 quilômetros interligando as cinco rodovias federais que cortam o Rio e que dão acesso a outros estados, com início das operações previsto para 2010; ii) a construção da Companhia Siderúrgica do Atlântico (CSA), no Distrito Industrial de Santa Cruz, no Rio de Janeiro, muito próximo a fronteira com o município de Itaguaí, com início da produção previsto já para o final de 2009; iii) a construção do Complexo Petroquímico do Rio de Janeiro, em Itaboraí, cujas obras foram iniciadas em 2009; iv) inúmeros empreendimentos imobiliários residenciais e comerciais.

Há que se refletir, também, sobre o impacto que novas políticas públicas de incentivo a habitação popular, como o programa 'Minha Casa, Minha Vida' e de distribuição direta de renda, como o Bolsa Família, têm sobre a reativação econômica da periferia. 
Como a mobilidade espacial da população é indissociável da mobilidade espacial dos bens de consumo e de produção, de capitais, de empresas, de tecnologias e de informações e ainda, como, segundo Lago (2000), no caso da mobilidade intra-urbana, a localização e relocalização do capital imobiliário e dos investimentos públicos na cidade assumem papel de destaque, há que se supor que as mudanças econômicas observadas na periferia sejam refletidas em novas formas de mobilidade.

Uma das mais evidentes expressões do aquecimento econômico da periferia da RMRJ é o imenso número de empreendimentos imobiliários residenciais lançados nestes municípios ao longo dos últimos anos. A maior parte deles reproduz o padrão característico dos condomínios exclusivos da Barra da Tijuca, no município núcleo da RMRJ, e são voltados para a população de classe média.

Traçar o perfil do morador destes condomínios é fundamental para dimensionar a capacidade de atração de migrantes destes novos lançamentos. Supõe-se que parte significativa destes moradores não sejam migrantes, tendo se deslocado entre bairros do município onde se localiza o empreendimento. Mas não se descarta a possibilidade de um percentual significativo dos moradores serem migrantes, principalmente oriundos de outros municípios da própria periferia metropolitana. E ainda, em razão de muitos bairros do subúrbio carioca serem fronteiriços com alguns dos municípios em que o mercado imobiliário está mais aquecido, considera-se provável que os lançamentos estejam atraindo moradores do núcleo metropolitano, embora em menor quantidade.

Nestes casos, os empreendimentos estariam impactando a mobilidade espacial da população no sentido de tornar os municípios da periferia atraentes para migrantes de diversas origens. Mas a valorização do solo nestes municípios periféricos de maior dinamismo econômico, reforçada pelos lançamentos imobiliários, pode se refletir no processo de invasãosucessão (Correa, 1996), em que os antigos moradores destas áreas, mais pobres, seriam empurrados para as "periferias da periferia", desta vez colocando os novos núcleos da periferia na condição de repulsores de população.

Para além da alteração dos padrões migratórios, há que se considerar ainda que o aquecimento do setor imobiliário se reflete também sobre os padrões dos deslocamentos cotidianos casa-trabalho. A concentração da construção destes empreendimentos em dois ou três municípios amplia consideravelmente a oferta de empregos no setor de construção civil, ocupados, em grande parte, por população de baixa renda e deve atrair para estes núcleos um volume razoável de trabalhadores residentes em outros municípios, que se deslocarão cotidianamente, ampliando a demanda dos serviços de transporte público que integram a periferia. Após a inauguração destes condomínios, amplia-se também a oferta de emprego em outros setores majoritariamente ocupados por população de baixa renda e possíveis moradores de outros municípios: porteiros, faxineiros, zeladores, domésticas, etc., avolumando ainda mais estes fluxos pendulares.

Reconhecendo os deslocamentos cotidianos ou pendulares como aspectos complementares do fenômeno metropolitano (Susino, 2000 apud Jardim\&Ervatti, 2007) e, concordando que as migrações pendulares ganham especificidades e finalidades a partir da estrutura e das mudanças da organização da economia e da sociedade (Harvey, 2005), a análise e comparação entre os deslocamentos pendulares e a metrópole e suas transformações tornam-se fundamentais para este estudo.

Na RMRJ, o impacto dos migrantes pendulares na população residente permaneceu praticamente o mesmo entre 1980 e 2000, em torno de 7,7\%, chegando em 2000 a aproximadamente 800 mil pessoas residentes na RM se deslocando para trabalhar ou estudar em outro município. 
O número de pessoas que se deslocam para outros municípios na RMRJ, exceto o do Rio de Janeiro, quase dobrou em 20 anos, o que pode ser um indicativo da saturação econômica da metrópole, assim como da origem de novos centros de consumo e de serviços, via criação de shoppings e a criação de novas unidades de ensino e estabelecimentos industriais nos municípios metropolitanos mais populosos, que seguem as mesmas tendências de centralização do Rio de Janeiro, em relação ao trabalho, a educação e ao lazer, se diferenciando, em seu interior, social, econômica e espacialmente. Estes aspectos estão relacionados, supõe-se, ao aumento da migração intrametropolitana e pendular entre esses municípios, especialmente em relação a Niterói, Nova Iguaçu, Duque de Caxias e São Gonçalo.

O município do Rio de Janeiro, entre 1980 e 2000, teve um incremento de $78 \%$ no numero de pessoas que trabalhavam ou estudavam em outro município, ou seja, em 1980 cerca de 24 mil pessoas exerciam a pendularidade do município para outro e em 2000 esse contingente chegou a aproximadamente 42 mil, ou seja, saíam do Rio de Janeiro para trabalhar ou estudar em outro município metropolitano. Esse aumento reflete-se no volume de pessoas que se deslocam para determinados municípios que em 1980 não tinham nenhuma representatividade neste fluxo e em 2000 passou a receber um número maior de pessoas oriundas do município do Rio de Janeiro, como Itaguaí, Nilópolis, Nova Iguaçu, São João de Meriti, além de Duque de Caxias e Niterói, que em 1980 já absorviam mão-de-obra da capital.

Considerando todas as transformações ocorridas na periferia da RMRJ ao longo da última década, é possível supor que a divulgação dos dados referentes à mobilidade espacial da população do Censo Demográfico 2010 revelarão não apenas a consolidação de padrões migratórios e de deslocamentos intrametropolitanos delineados nas décadas anteriores como também devem apontar para a redução da pendularidade periferia-centro-periferia e para a ampliação da pendularidade periferia-periferia-periferia.

\section{NOTAS}

1- Este trabalho refere-se ao Projeto de Pesquisa de Doutoramento do autor, em desenvolvimento no curso de doutorado do Programa de Pós-Graduação em Geografia da UFRJ.

2- Segundo Kowarick (1983) e Ribeiro e Lago (1992), a literatura dos anos 70 e 80 destacou o caráter dual do padrão centro-periferia, marcado pela distância física e social entre as classes. A concentração do emprego, da moradia das classes médias e superiores, e dos equipamentos e serviços urbanos nas áreas centrais e, conseqüentemente, as enormes carências que marcavam os espaços periféricos sustentaram, até os anos 80 , esta visão.

\section{REFERÊNCIA BIBLIGRÁFICAS}

BROWETT, J. On the Necessity and Inevitability of Uneven Spatial Development under Capitalism. International Journal of Urban and Regional Research, 8 (2). 1984.

CORREA, R. L. O Espaço Urbano. São Paulo. Ed. Ática. Série Princípios, 1989. 
.Diferenciação Sócio-Espacial, Escala e Práticas Espaciais. Texto para Discussão. GEU (Grupo de Estudos Urbanos).Departamento de Geografia. UFRJ. Outubro 2006. (Inédito).

DAVIDOVICH, F. “A volta da Metrópole no Brasil: Referências para a gestão territorial”. In: Metrópoles: Entre a coesão e a fragmentação, a cooperação e o conflito. Luiz César de Queiroz Ribeiro (org.).São Paulo. Ed. Fundação Perseu Abramo. Rio de Janeiro. FASE. p.197-229. 2004.

HARVEY, D. Class Structure in a Capitalist Society and the Theory of Residential Differentiation, In.: Processes in Physical and Human Geography, ed. R. Peel, M. Chisholm e P. Haggett. Heinemann Educational Books, Londres, 354-369, 1975.

JARDIM, A.P e ERVATTI, L. "Migração pendular intrametropolitana no Rio de Janeiro; reflexões sobre o seu estudo, a partir dos Censos Demográficos de 1980 e 2000" Texto para discussão n.26. Rio de Janeiro, IBGE, COPIS, 2007.

JARDIM, A.P. Algumas reflexões sobre o estudo das migrações pendulares. In.: Anais do $\mathrm{V}$ Encontro Nacional Sobre Migrações, 2007.

KOWARICK, L. A espoliação urbana. São Paulo, Paz e Terra, 1983.

LAGO, L.C. Desigualdades e segregação na metrópole: o Rio de Janeiro em tempo de crise. Rio de Janeiro: Revan: Fase, 2000.

O mercado de trabalho na metrópole do Rio de Janeiro: a periferia que virou centro. In.: Anais do XXII Encontro Nacional de Estudos Populacionais, 2008.

OLIVEIRA, A.T.R. "Fluxos migratórios na Região Metropolitana do Rio de Janeiro". In: Helion Povoa Neto \& Ademir Pacelli Ferreira (orgs.).Cruzando fronteiras disciplinares. Um panorama dos estudos migratórios. NIEM-RJ. FAPERJ. Ed. Revan. 2005. p.349-363.

SANTOS, M. A urbanização brasileira. São Paulo. Ed. Hucitec. 1996.

WALKER, R. Two sources of uneven development under advanced capitalism: spatial differentiation and capital mobility. The Review of Radical Political Economics, 10 (3). 1978. 